$1-15-2010$

\title{
Constitutive Response and Mechanical Properties of PFSA Membranes in Liquid Water
}

\author{
Ahmet Kusoglu \\ University of Delaware \\ Yaliang Tang \\ University of Delaware \\ Melissa Lugo \\ University of Delaware
}

Anette M. Karlsson

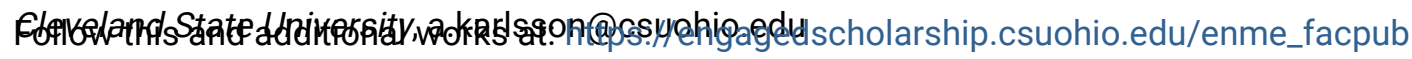

JPlareloffthealpltarteanical Engineering Commons

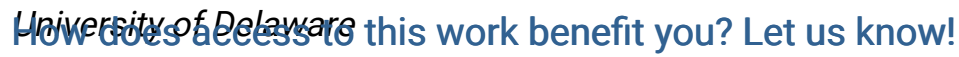

\section{Publisher's Statement}

SOThCE: this is the author's yersion of a work that was accepted for publication in Journal of Power Sources. Changes resulting from the publishing process, such as peer review, editing, corrections, structural formatting, and other quality control mechanisms may not be reflected in this document. Changes may have been made to this work since it was submitted for publication. A definitive version was subsequently published in Journal of Power Sources, 195, 2, (01-15-2010); 10.1016/j.jpowsour.2009.08.010

\section{Original Citation}

Kusoglu, A., Tang, Y., Lugo, M., 2010, "Constitutive Response and Mechanical Properties of PFSA Membranes in Liquid Water," Journal of Power Sources, 195(2), pp. 483-492.

This Article is brought to you for free and open access by the Mechanical Engineering Department at EngagedScholarship@CSU. It has been accepted for inclusion in Mechanical Engineering Faculty Publications by an authorized administrator of EngagedScholarship@CSU. For more information, please contact library.es@csuohio.edu. 


\section{Authors}

Ahmet Kusoglu, Yaliang Tang, Melissa Lugo, Anette M. Karlsson, Michael H. Santare, Simon Cleghorn, and William B. Johnson 


\title{
Constitutive response and mechanical properties of PFSA membranes in liquid water
}

\author{
Ahmet Kusoglu ${ }^{a}$, Yaliang Tang ${ }^{\mathrm{a}}$, Melissa Lugo ${ }^{\mathrm{a}}$, Anette M. Karlsson ${ }^{\mathrm{a}, *}$, \\ Michael H. Santare ${ }^{a}$, Simon Cleghorn ${ }^{\text {b }}$, William B. Johnson ${ }^{\text {b }}$ \\ a Department of Mechanical Engineering, University of Delaware, Newark, DE 19716, United States

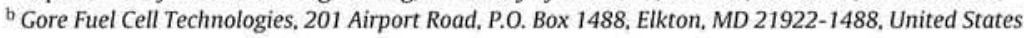

\section{Introduction}

Perfluorosulfonic acid (PFSA) ionomers are commonly used as the electrolyte in proton exchange membrane fuel cells (PEMFCs) due to their high proton conductivity, good chemical stability. and mechanical integrity. For this class of materials, the degree of hydration strongly influences the mechanical and physical properties. The proton conductivity is dramatically enhanced by hydration, and the mechanical properties of the membrane are directly linked to the water uptake [1-6], which in turn influences the mechanical behavior of the membrane and fuel cell longevity [7-12]. For example, mechanical failures in membrane electrode assemblies (MEAs) have been precipitated solely by cycling between wet and dry operating conditions without electric potential or reactive gases $[10,13,14]$. Furthermore, water absorption of a partially constrained membrane during fuel cell operation results in swelling-induced stresses that may affect the long-term mechanical behavior and durability of the membranes $[2,11,12,15,16]$. Thus, characterizing the mechanical behavior of swollen PFSA membranes is important for understanding the

\footnotetext{
* Corresponding author. Tel.: +1 3028316437.

E-mail address: karlsson@udel.edu (A.M. Karlsson).
}

mechanical response of polymer electrolyte membranes (PEMs) and to the development of new PFSA-based membranes for fuel cell applications. In particular, it is important to obtain a mathematical formulation of the constitutive response so that the membrane response can be incorporated into mechanics-based modeling efforts.

A swollen PFSA membrane can be characterized as vaporequilibrated if the membrane is equilibrated in air (or another gas) with a given relative humidity (RH); and liquid-equilibrated (wet) if the membrane is immersed in and equilibrated with liquid water. Some researchers [17-20] have suggested that the capacity for water uptake of a membrane in saturated water vapor (at $100 \%$ relative humidity) differ from that in liquid water at the same temperature, e.g. Schroeder's paradox [21], a subject of debate in the literature [17-19,22-25]. A complete investigation on this topic is beyond the scope of the current work. Thus, we will in the discussion that follows distinguish between if the membrane has been equilibrated in saturated water vapor or in liquid water and how this affects the deformation behavior of the membrane. We believe this will give further insight and lead the way toward an unraveling of Schroder's paradox.

The phase of the external water (e.g. vapor vs. liquid), as well as membrane pretreatment procedures, have been shown to cause significant changes in the measured physical $[18,23,25,26]$ 
and mechanical properties [6,27-29]. The mechanical response of Nafion ${ }^{\circledR}$ membranes ${ }^{1}$ at various degrees of swelling has recently been a focus of a number of studies [1-3,5,6,27-30]. The constitutive response of PFSA-based membranes swollen at various temperatures and hydration levels for various ions were investigated by Kawano et al. [6] and Kundu et al. [29] based on measurements from a dynamic mechanical analyzer. Experimental data on the temperature and humidity dependent tensile stress-strain response was reported by Tang et al. [1] and later by Solasi et al. [2] for Nafion ${ }^{\circledR} 112$ and 111 membranes, respectively. Liu et al. [3] studied the tensile loading and stress-relaxation behavior of vapor-equilibrated Nafion ${ }^{\circledR} 117$ membranes, examining the effects of strain rate and counterion type. Solasi et al. [27] developed a viscoplastic model to reproduce the experimental results for the strain-rate dependence and the stress-relaxation behavior of the membrane. Recent work by Majsztrik et al. [4] and Satterfield and Benziger [28] focused on the experimental and theoretical investigation of the time-temperature-dependent viscoelastic response of PFSA membranes swollen at various humidities. In addition, the structural transformation of PFSA membranes has been studied at meso- and nano-scales and at various stretch ratios [31,32]. Kusoglu et al. [30] showed that the characteristic features of the tensile stress-strain curve of the vapor-equilibrated PFSA membranes, i.e. membranes swollen in water vapor (humid air) at a controlled humidity, can be captured by G'Sell-Jonas constitutive model [33] at various humidities and temperatures. However, the constitutive behavior of liquid-equilibrated PFSA membranes has yet to be described in detail. Even though the vapor-to-liquid transition of PFSA membranes has been described in the literature through water sorption mechanisms and/or nanostructural changes [18,25,26,34-37], the associated effects on the constitutive response has not been investigated.

In this work, the constitutive behavior and water uptake of liquid-equilibrated PFSA membranes are investigated by means of tensile testing of Nafion ${ }^{\circledR} 112$ membranes in a custom-built temperature-controlled water bath and compared with our previous work on vapor-equilibrated membranes [1,30]. We will first explore the effect of vapor-to-liquid transition on the resulting constitutive behavior and then show that the experimentally obtained behavior can be characterized via the large-deformation constitutive equations of rubber-like materials defined by Mooney [38], Rivlin [39] and Ogden [40]. Based on these formulations, the material parameters for each model are obtained by matching the experimental uniaxial stress-strain data to the theory at tested temperatures. Finally, the theory of nonlinear rubber viscoelasticity is used to investigate the relaxation behavior of PFSA membranes immersed in water at room temperature.

\section{Experiments}

\subsection{Experimental setup}

We conducted ex situ tensile tests of pretreated Nafion ${ }^{\circledR} 112$ membrane (nominal thickness of $52 \mu \mathrm{m}$ and equivalent weight (EW) of $1100 \mathrm{~g} \mathrm{~mol}^{-1}$ ), in a custom-built water bath with a temperature-controlled heater fitted to an MTS Alliance ${ }^{\mathrm{TM}} \mathrm{RT} / 5$ material testing system. The membranes are pretreated by boiling in $3 \%$ hydrogen peroxide, $0.5 \mathrm{M}$ sulfuric acid and deionized water (DI), respectively, for $1 \mathrm{~h}$ each followed by drying at room temperature for $24 \mathrm{~h}$. The tensile test setup is shown in Fig. 1 [1]. Due to the processing conditions, two distinct material directions

\footnotetext{
1 Nafion ${ }^{\circledR}$ membrane is a commercially available PFSA-based membrane commonly used in PEMFC applications. Nafion is a registered trademark of E.I. DuPont De Nemours \& Co.
}

exist in the plane of the membrane: machine direction (MD) and transverse direction (TD). Consequently, at each temperature, five specimens were tested in each of the directions. The specimen was aligned with the machine axis and clamped in a pair of vise-action grips (Fig. 1) so that the gauge length was approximately $50 \mathrm{~mm}$ as determined by the grip separation. After the bath was filled with distilled water, the temperature was increased to the desired temperature and allowed to stabilize. During this process the membrane expands due to the water absorption. When the temperature had stabilized, we manually adjusted the crosshead until the compressive stress, developed in the specimen due to swelling, was brought back to zero. The crosshead change is assumed as the inplane dimensional change of the membrane in liquid water at the temperature investigated, and the new, total length is the undeformed swollen length, $L^{\mathrm{sw}}$, which is also used as the gauge length of the specimen for the calculation of the strain due to loading. The swelling strain, $\varepsilon^{s w}$, is defined as the change in the undeformed swollen length with respect to membrane's initial length before any water uptake, $L^{\text {dry }}$ :

$\varepsilon^{\mathrm{sw}}=\frac{L^{\mathrm{sw}}}{L^{\mathrm{dry}}}-1$

A constant crosshead displacement rate of $0.2 \mathrm{~mm} \mathrm{~min}^{-1}$ was used throughout the tests. Stress and strain were then calculated from the force-displacement data recorded during the tensile testing. Typically, strains are reported as engineering strains, $\varepsilon^{\mathrm{eng}}=\Delta L / L^{\mathrm{sw}}$, i.e. the change in the length of the deformed, swollen membrane, $\Delta L^{\mathrm{sw}}$, with respect to the initial, undeformed swollen length, $L^{\mathrm{sw}}$. However, true strain is a more accurate measure - in particular for large-deformations - and is determined from the relation:

$\varepsilon=\ln \left(1+\varepsilon^{\mathrm{eng}}\right)=\ln \left(1+\frac{\Delta L^{\mathrm{sw}}}{L^{\mathrm{sw}}}\right)$

As an alternative measure of deformation, the stretch ratio is defined by

$\Lambda=1+\varepsilon^{\mathrm{eng}}=\exp (\varepsilon)$

For each specimen equilibrated in liquid water (before tensile testing), we measured the swollen thickness, $t^{\mathrm{sw}}$, and swollen width, $w^{\mathrm{sw}}$, at three locations along the membrane with a micrometer and a caliper, respectively, and used the averages of these three measurements as the nominal dimensions of the membrane swollen in liquid water. The engineering stress, $\sigma^{\mathrm{eng}}$, is then calculated by dividing the measured force, $F$, by the swollen cross-sectional area normal to the loading direction, i.e.:

$\sigma^{\mathrm{eng}}=\frac{F}{A^{\mathrm{sw}}}=\frac{F}{t^{\mathrm{sw}} W^{\mathrm{sw}}}$

Also, in order to obtain an accurate description of the stress, we use true stress, $\sigma$ :

$\sigma=\left(1+\varepsilon^{\mathrm{eng}}\right) \sigma^{\mathrm{eng}}$

Using the stress-strain data, Young's modulus, E, was determined for each of the specimen in liquid water at the specified temperature. Also, we determine the total volumetric strain due to water uptake from the swelling measurements in three directions and convert this measure to the polymer volume fraction of the sample, i.e.:

$\phi_{\mathrm{p}}=\frac{V^{\mathrm{dry}}}{V^{\mathrm{sw}}}$

The (initial) dry thickness was set to the thickness measured after the specimens dried in a vacuum furnace at $50^{\circ} \mathrm{C}$ for $2 \mathrm{~h}$.

In addition to the monotonic tensile tests establishing the ex situ constitutive response during loading, we conducted a limited set of time-dependent (ex situ) experiments of PFSA membranes in liquid 


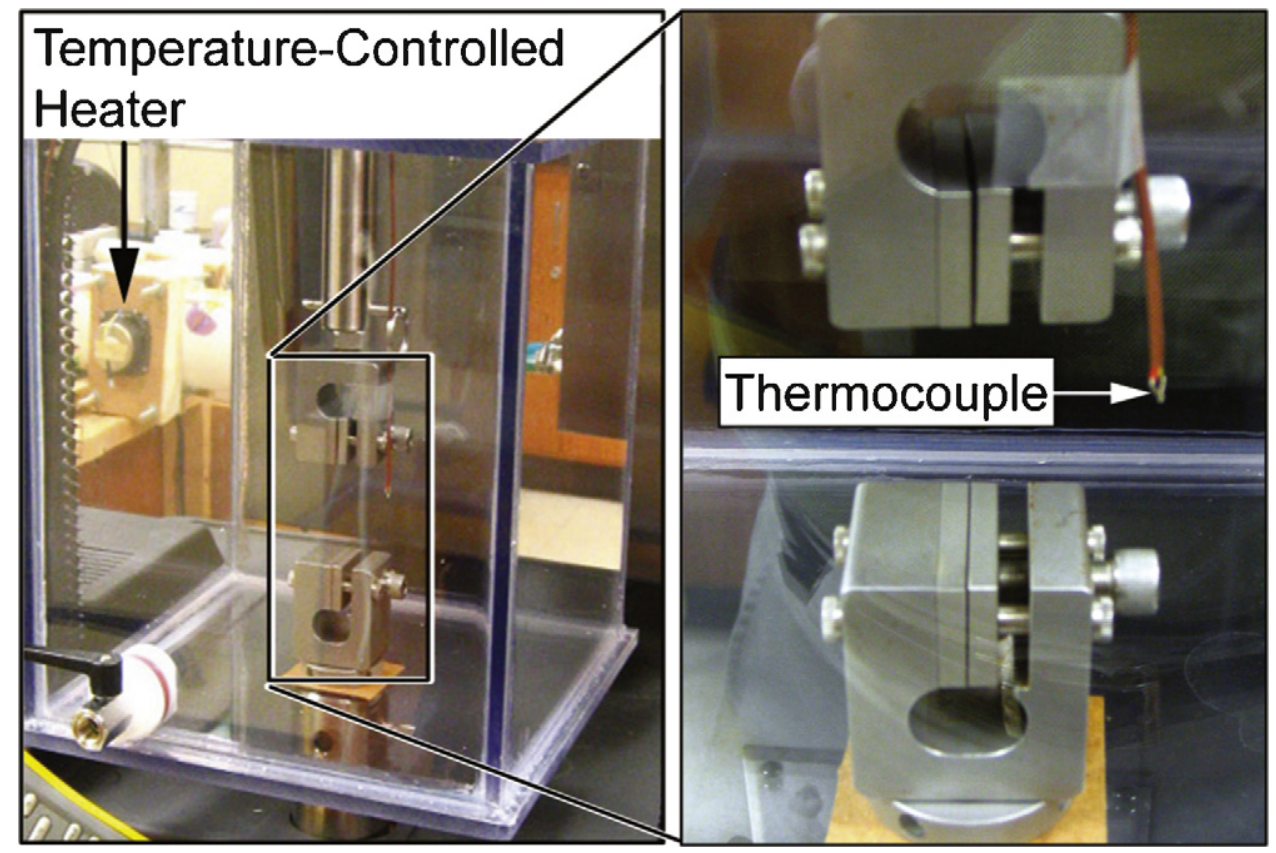

Fig. 1. Experimental setup: MTS Alliance RT/5 material testing system with a custom-built water bath with temperature-controlled heater.

water to investigate the relaxation behavior. These relaxation tests were conducted at room temperature $\left(T=25^{\circ} \mathrm{C}\right)$ with strain ratios of $\varepsilon_{0}=0.2$ and 0.5 . The strain ratios were imposed at the beginning of the relaxation tests and held throughout the relaxation period, while the change in the stress was continuously monitored.

\subsection{Experimental results}

The in-plane swelling in liquid water for the machine direction is graphed in Fig. 2 together with the previously reported swelling in humid air at various relative humidities and selected temperatures [1]. The graphs show the average values of the five measured specimens and in each case, the standard deviation is less than $10 \%$ of the average. The swelling coefficient (the slope of the curve) increases with increasing humidity (Fig. 2). The membrane swells almost twice as much in liquid water as in humid air at $90 \%$ relative humidity. We note an increase in the swelling strain with increas-

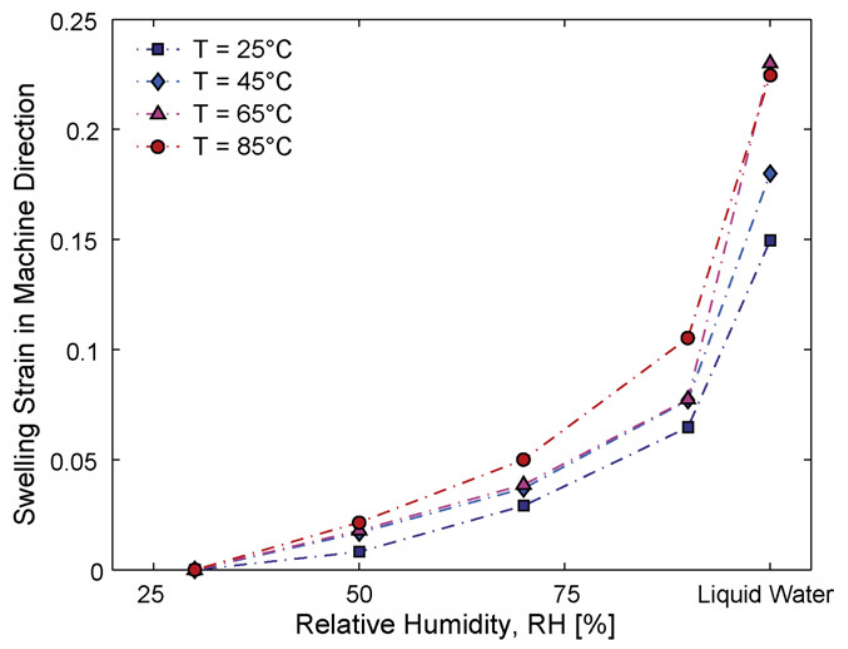

Fig. 2. In-plane swelling strain along the machine direction as a function of relative humidity and in liquid water at various temperatures (lines are guide for the eye only). ing temperature for a given relative humidity (Fig. 2). This effect is far greater than expected from thermal expansion alone since the thermal strain of PFSA membranes in this temperature range is on the order of 0.01 [41]. Therefore, the results suggest that the water sorption behavior of PFSA membranes is affected directly by humidity and temperature.

Swelling strains of PFSA membrane in liquid water are depicted as a function of temperature in Fig. 3 in all three directions; i.e. machine, transverse and thickness. These swelling strains correspond to water volume fractions of $\phi_{\mathrm{w}}=0.39-0.44$ at room temperature, in agreement with values reported in the literature $[18,25,26,36,37,42]$. The increase in length due to water uptake is larger along the transverse direction than the machine direction, although the trends are similar. Our measurements suggest that the swelling of PFSA membranes in liquid water is nearly isotropic.

Fig. 4 shows the typical engineering stress-strain behavior for the PFSA membrane along the machine direction at four temper-

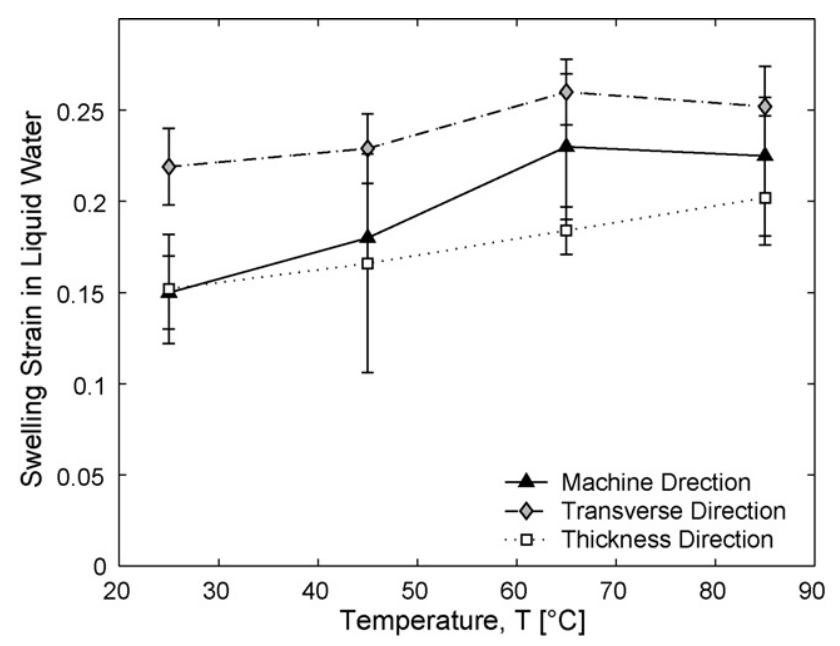

Fig. 3. Swelling strain due to water uptake in liquid water as a function of temperature along machine, transverse and thickness directions (lines are guide for the eye only). 


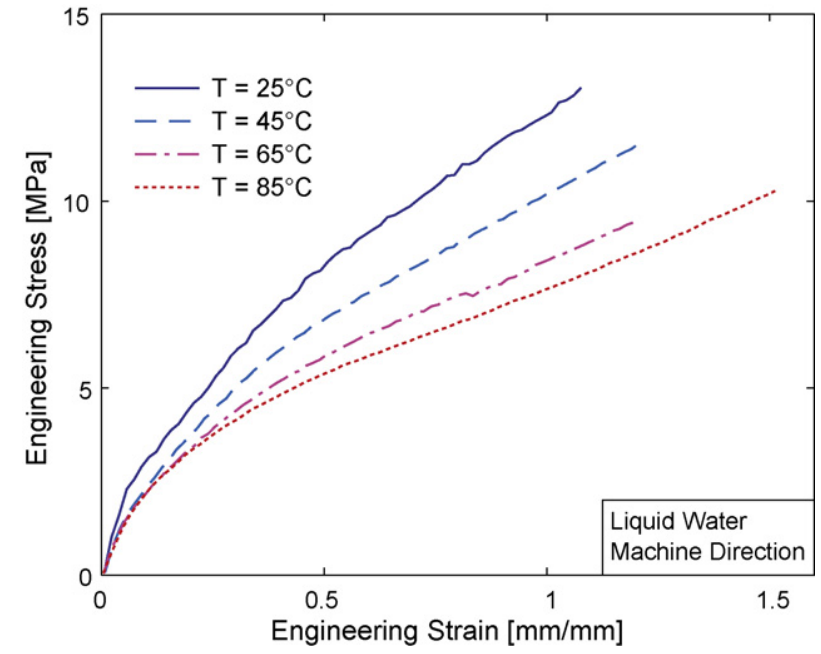

Fig. 4. Engineering stress as a function of engineering strain for tensile tests at 25 , 45,65 and $85^{\circ} \mathrm{C}$ in liquid water (machine direction).

atures in liquid water. The curves shift monotonically downward with increasing temperature, corresponding to a decrease in tensile stiffness and strength as the temperature increases. This temperature-driven decrease in stiffness and strength was also observed in the tests conducted in water vapor (humid air) conditions as discussed in Ref. [1]. Since an increase in the temperature causes higher swelling strains (Fig. 3), the temperature-driven softening mechanisms in the swollen polymer may be attributed to the increasing mobility of polymer chains at elevated temperatures. Selected results from our previous tests in water vapor (humid air) [1] are compared to tests in liquid water in Fig. 5. The initial stiffness decreases with increasing humidity and reaches the lowest level in liquid water. However, in the next section we will show that, the constitutive response of the PFSA membrane appears to be fundamentally different in liquid water than in water vapor. We note here the importance of using the correct (water swollen) cross-sectional area in the stress calculations: stress-strain curves determined without properly correcting for the swollen area (i.e. force divided by dry area) incorrectly show an apparent

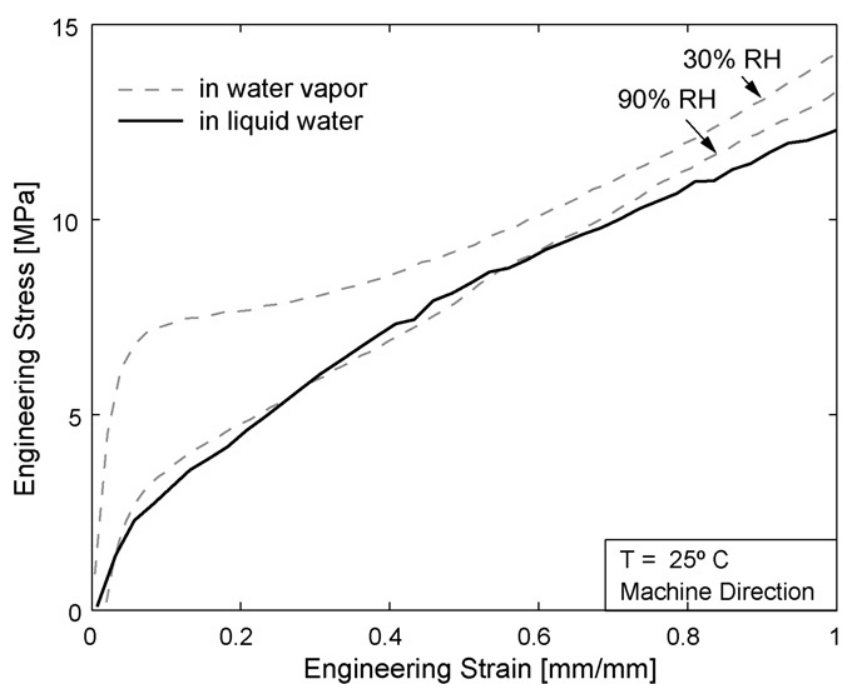

Fig. 5. Engineering stress as a function of engineering strain for tensile tests conducted at various relative humidities [1] and in liquid water at $25^{\circ} \mathrm{C}$ in the machine direction.

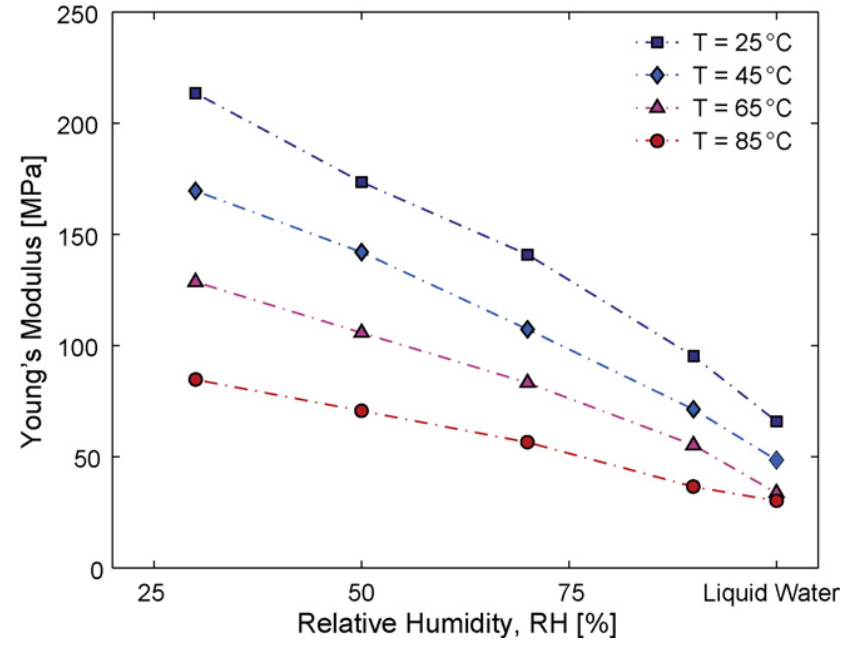

Fig. 6. Young's modulus as a function of relative humidity at various temperatures (machine direction) (lines are guide for the eye only).

higher strain-hardening in liquid water than in water vapor (humid air).

Young's modulus is determined by measuring the slope of the initial linear response (as detailed in Ref. [1]) of each engineering stress-strain curve, and is summarized at selected temperatures in Fig. 6 . The experimental data previously obtained in humid air at various temperatures and humidities [1] are included for comparison. The results suggest that Young's modulus is lower in liquid water than in $90 \%$ humid air, and indicates a continuous decrease with increasing water content (Fig. 6). However, in liquid water, the effect of temperature on Young's modulus is less pronounced when compared to that in humid air (Fig. 6).

The tensile relaxation data for PFSA membranes immersed in liquid water at $T=25^{\circ} \mathrm{C}$ are depicted in Fig. 7. The membranes reach different equilibrium stresses under different applied strains. When the applied strain is increased by a factor of 2.5 (from 0.2 to 0.5 ) the equilibrium stress increases only by a factor of 2 , which indicate a strain-dependent relaxation response. This behavior will be discussed in Section 4.3.

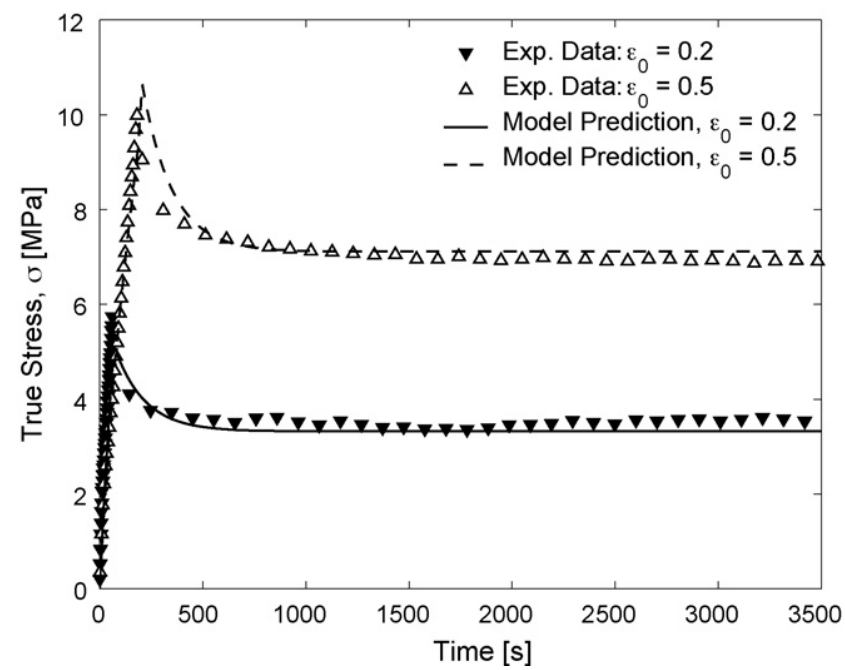

Fig. 7. True stress as function of time for two selected hold stains: predictions of the nonlinear viscoelasticity model for the stress relaxation of the liquid-equilibrated PFSA membrane at $T=25^{\circ} \mathrm{C}$ are compared to the experimental data (machine direction). 


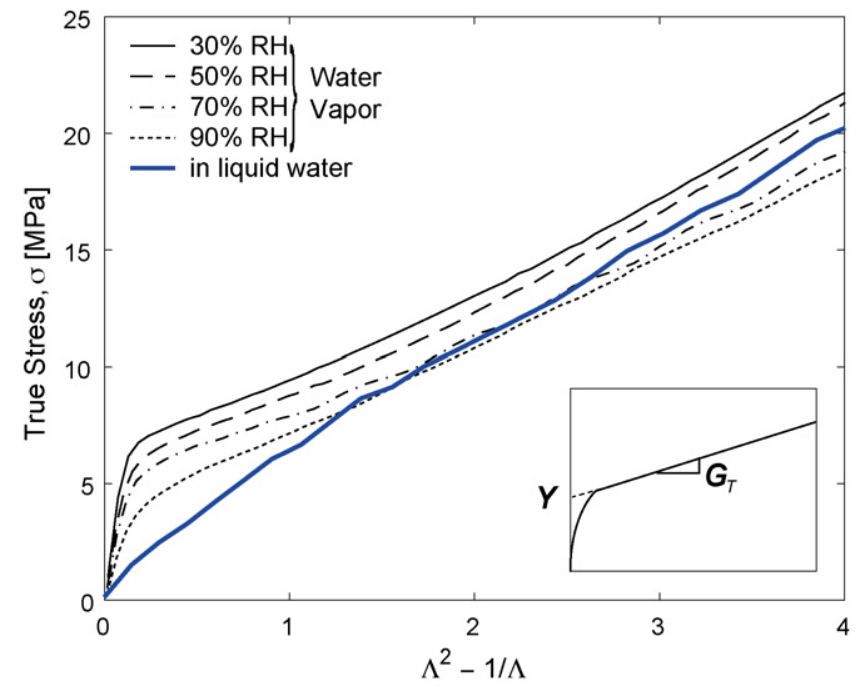

Fig. 8. True stress as a function of stretch measure, $\Lambda^{2}-1 / \Lambda$, for vapor-equilibrated (at four relative humidities, from [1]) and liquid-equilibrated PFSA membrane plotted at $T=25^{\circ} \mathrm{C}$ (transverse direction).

\subsection{Discussion of experimental results}

In our previous work, we showed that the constitutive response of PFSA membranes in water vapor (humid air) corresponds to that of semicrystalline polymers [30]. This behavior includes an initial linear (Hookean) regime, followed by the onset of nonlinearity (which can be associated with the initiation of yielding) and strain-induced hardening at larger strains [1-3,6,30]. A modified form of the G'Sell-Jonas (GJ) constitutive model for semicrystalline polymers accurately describes the experimental tensile test data obtained at various humidities, especially at low strains and low humidities [30]. However, the accuracy of the GJ model predictions decreases at large-deformations $(\varepsilon>0.5)$. In addition, the GJ model fails to capture the tensile response of liquid-equilibrated PFSA membrane, suggesting that the liquidequilibrated PFSA membrane does not exhibit the characteristic features of a semicrystalline polymer.

Haward and Thackray $[43,44]$ developed a model to describe the large strain response of semicrystalline thermoplastics. This model assumes that the large plastic strains can be modeled using equations describing rubber elasticity. For uniaxial tension of semicrystalline polymers subjected to large plastic strains, the Haward-Thackray constitutive relation is [43]:

$\sigma=Y+G_{T}\left(\Lambda^{2}-\frac{1}{\Lambda}\right)$

where $\sigma$ is the true stress, $Y$ is the extrapolated yield limit, $G_{T}$ is the strain-hardening modulus, and $\Lambda=\varepsilon^{\mathrm{pl}} \approx 1+\varepsilon$ is the plastic stretch which can be approximated by the total stretch for materials with small elastic strains. In semicrystalline polymers, the second term predicts the hardening corresponding to the plastic deformation. However, in an ideal rubber, $Y \rightarrow 0$ and it follows that the second term in Eq. (7) characterizes the elastic response of an ideal, Gaussian material. ${ }^{2}$ In this case, $G_{T}$ becomes the shear modulus of the ideal rubber, $G$.

Experimental stress data for vapor-equilibrated [1] and liquidequilibrated Nafion ${ }^{\circledR} 112$ membrane are plotted in Fig. 8 as a function of $\Lambda^{2}-1 / \Lambda$ at $25^{\circ} \mathrm{C}$ for the transverse direction. In this

${ }^{2}$ A Gaussian material is a hypothetical polymer network in which the end-toend distance of the polymer chains can be represented by a Gaussian distribution function.

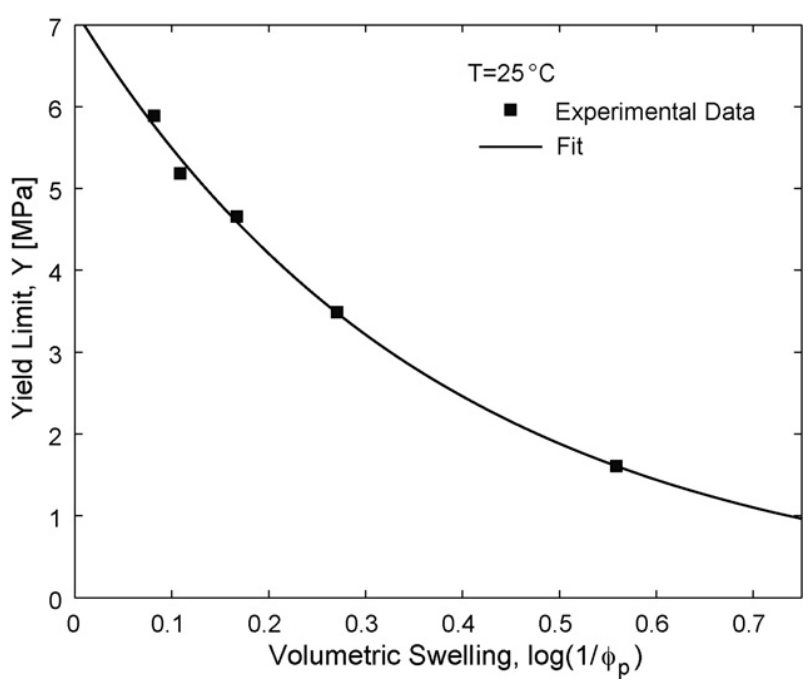

Fig. 9. Extrapolated yield limit, $Y$, as a function of polymer volume fraction at $25^{\circ} \mathrm{C}$ (transverse direction).

work, we will assume that the onset of nonlinearity corresponds to the yield limit, $Y$. The yield limit, $Y$, can be obtained empirically by extrapolating the linear response (after the onset of yielding) back to zero strain. Fig. 8 shows that a non-vanishing $Y^{\text {vap }}$ is obtained for vapor-equilibrated membranes using this method. However, the yield limit in liquid water, $Y^{\text {liq }}$, is very low suggesting a response similar to the elastomers for liquid-equilibrated membrane. Thus, even though PFSA is not an elastomer, the constitutive response used for modeling rubbery behavior can be used for describing the constitutive response of PFSAs with high water content.

The relationship between the yield limit, $Y$, and the polymer volume fraction, $\phi_{\mathrm{p}}$, at room temperature (Fig. 9) can be characterized by the following empirical relationship:

$\frac{Y}{Y^{\mathrm{dry}}}=\phi_{\mathrm{p}}^{\mathrm{m}}$

where the model parameters $Y^{\mathrm{dry}}=7.17 \mathrm{MPa}$ and $m=2.67$ are the yield limit of the membrane in dry state $\left(\phi_{\mathrm{p}}=1\right)$ and power exponent, respectively, for transverse direction. In liquid water, the yield limit is approximately $1.5 \mathrm{MPa}$ independent of the temperature (Fig. 10).

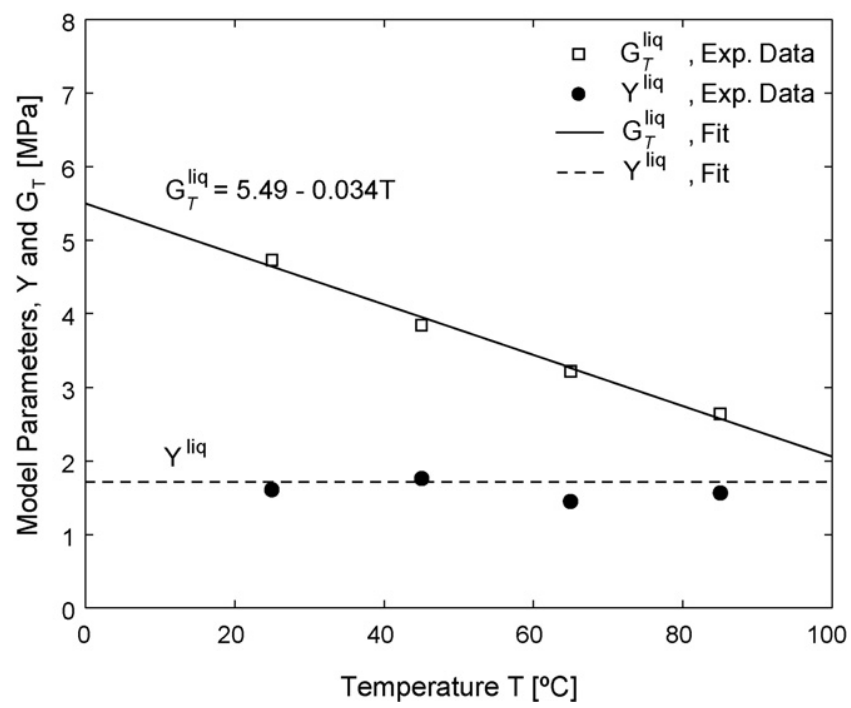

Fig. 10. Yield limit, $Y^{\mathrm{liq}}$, and strain-hardening modulus, $G_{T}^{\text {liq }}$, for liquid-equilibrated PFSA membrane as a function of temperature (transverse direction). 
In addition, the hardening behavior for vapor-swollen PFSA membranes appears to be independent of humidity (Fig. 8) with a hardening modulus of $G_{T}^{\mathrm{vap}}=1.1 \pm 0.1[\mathrm{MPa}]$. The constitutive response of the vapor-swollen PFSA membranes at other temperatures [30] exhibits a similar value for $G_{\mathrm{T}}^{\mathrm{vap}}$ independent of water content (not shown). However, a clear increase in the slope can be seen for the curves in liquid water, when compared to those in humid air (Fig. 8). Furthermore, the decrease in the hardening modulus in liquid water, $G_{\mathrm{T}}^{\text {liq }}$, with increasing temperature, $T$ (Fig. 10) can be described empirically by the affine relationship:

$G_{T}^{\operatorname{liq}}(T)=5.5-0.034 T$

In summary, a continuous decrease in the onset of initial nonlinearity is observed with increasing temperature and swelling, from humid air to liquid water conditions, $Y^{\mathrm{vap} \rightarrow \operatorname{liq}}=Y^{\mathrm{vap} \rightarrow \operatorname{liq}}\left(T, \phi_{\mathrm{p}}\right)$. However, in liquid water, the effect of temperature on the yield limit vanishes, $Y^{\mathrm{liq}}(T)=Y^{\mathrm{liq}}$, see Fig. 10 . In contrast, the hardening modulus appears to be constant in humid air independent of the temperature and swelling, $G_{T}^{\mathrm{vap}}\left(T, \phi_{\mathrm{p}}\right)=G_{T}^{\mathrm{vap}}$, whereas it increases in liquid water $G_{T}^{\text {liq }}>G_{T}^{\text {vap }}$ (as can be seen from the slope of the curves in Fig. 8), and exhibits temperature dependence (see Eq. (9)). Together, these results suggest that the constitutive response of the liquid-equilibrated membrane changes significantly compared to that of vapor-equilibrated membranes, especially for low to moderate strains.

Thus, in summary, important aspects of the constitutive response of liquid-equilibrated PFSA membranes include that the onset of nonlinearity is not readily discernable (i.e. a very low yield limit, $Y^{\text {liq }}$ ), and that the hardening modulus is higher than that of vapor-equilibrated membranes. In the following, we will further investigate this type of constitutive behavior by comparing to the standard models of rubber-like polymers.

\section{Theoretical models for constitutive response of rubber-like polymers}

Inspection of the stress-strain curves obtained for the PFSA membrane in liquid water indicate a clear similarity to the response observed for rubber-like polymers subjected to largedeformations, even though PFSA membrane is not a rubber. We do not claim that PFSA membrane is a typical rubber. We will rather show here that the constitutive equations developed for such behavior capture our experimental data for the liquid-equilibrated PFSA membranes quite well. In this section, we will briefly review the most commonly used theories of rubber-like deformation and in the next section we will compare these equations to our experimentally obtained data.

Various theoretical models have been proposed to capture the large-deformation behavior of rubber-like materials. Early models include formulations based on statistical theory of rubber elasticity by James and Guth $[45,46]$ and Mooney [38]; as well as strain energy formulations by Rivlin [39] and later by Ogden [40]. Additional models have been introduced over time (for example, Weiner and Gao [47], Treloar [48], Boyce and Arruda [49], James and Guth [50], Meissner [51] and Bloch et al. [52-54]). Limited information is available on the time-dependent deformation behavior of the vapor-equilibrated PFSA membranes $[4,27]$. Our preliminary results suggest a highly nonlinear mechanical behavior for PFSA membranes in liquid water, but a full investigation on the timedependence is left as a subject for future studies.

\subsection{Mooney-Rivlin theory and formulation}

According to Rivlin [39], the strain energy function for an incompressible elastomer can be written as a function of the first and second strain invariants. For uniaxial extension of an incompressible, isotropic material, let the stretch ratio in the direction of the applied force be $\Lambda$. Then, true stress, $\sigma$, can be written as $[38,39,48]$ :

$\sigma=\left(\Lambda^{2}-\frac{1}{\Lambda}\right)\left(2 C_{1}+\frac{2 C_{2}}{\Lambda}\right)$

where $C_{1}, C_{2}$ are the two empirical material constants. For the special case of $C_{2}=0$, Eq. (10) represents the behavior of a Gaussian polymer chain network. The term $C_{2}$ represents the deviation from this idealized behavior $[38,48]$. Eq. (10) can be rewritten in the following form:

$\sigma_{\mathrm{rs}} \equiv \frac{\sigma}{\Lambda^{2}-1 / \Lambda}=2 C_{1}+2 C_{2} \frac{1}{\Lambda}$

where $\sigma_{\mathrm{rs}}$ is the reduced stress (or Mooney stress [38]). The plot of reduced stress as a function of the reciprocal stretch ratio, $1 / \Lambda$, corresponds to a straight line with a slope of $2 C_{2}$ for an ideal Mooney-Rivlin (MR) material. The two-parameter Mooney equation is based on the assumption that the material behavior is linear elastic in simple shear [38]. Therefore, for an isotropic, incompressible material obeying Eq. (11), Young's modulus is $E=6\left(C_{1}+C_{2}\right)$.

\subsection{Ogden's formulation}

Ogden proposed an alternative strain energy formulation for the elastic behavior of rubbery polymers in terms of the principal extension ratios rather than the strain invariants [40]. For uniaxial deformation, the true stress, $\sigma$, in the stretching direction can be described as [40]:

$\sigma=\sum_{n} \mu_{n}\left(\Lambda^{\alpha_{n}}+\Lambda^{-\alpha_{n} / 2}\right)$

where $\mu_{n}, \alpha_{n}$ are empirical material parameters. For a physically reasonable response, the inequality $\mu_{n} \alpha_{n}>0$ must be satisfied [40]. For pure shear, Eq. (12) suggests $\sum \mu_{n} \alpha_{n}=2 G$, with $G$ being the shear modulus. This is consistent with the classical theory of isotropic elasticity.

Using the Ogden model (OM), a more accurate representation of the deformation behavior of a polymer can be obtained by including additional material parameters. This requires more than one type of experiment. However, Ogden showed that a reasonable prediction of the tensile behavior of rubber-like materials can usually be made with just a few terms [40].

\subsection{Nonlinear viscoelasticity of rubber-like polymers}

In order to model the measured relaxation behavior (Fig. 7) we will briefly investigate the theory of viscoelasticity as applied to rubber-like polymers. Time-dependent, nonlinear deformation of rubber-like materials is not well-established due to the complex nature of the problem [55,56]. Here, the term nonlinear refers to the stress-strain response. In viscoelasticity, the term linearity also refers to the time-dependence, which is associated with the use of the Boltzmann superposition principle [55-57]. According to this principle, the response at the current time, $t$, is the sum of the responses to all strains or excitations applied previously. Experimental observations suggest that time-dependent linearity generally holds for most rubber-like materials even when the stress-strain response is nonlinear [52]. Chang et al. [53,58] proposed a phenomenological description for the large-deformation, nonlinear viscoelastic behavior of rubbery materials by decoupling the effects of time and strain, and introducing a generalized (finite) strain measure into the Boltzmann superposition integral 

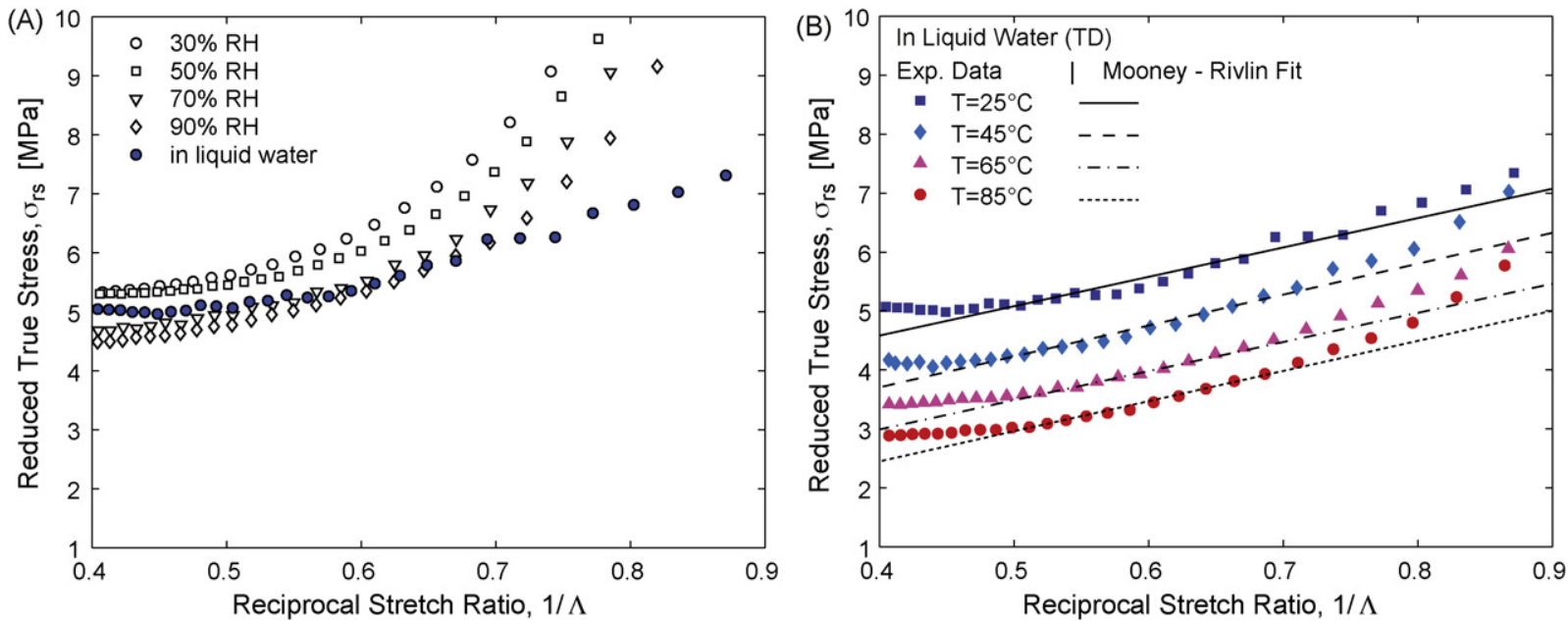

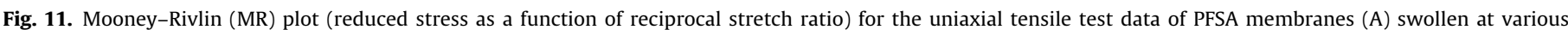

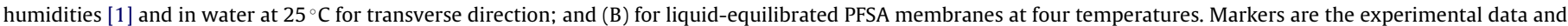
solid lines are the model prediction (transverse direction).

[52,53], i.e.:

$\sigma(t)=\frac{2}{3} \int_{0}^{t} E(t-\tau)\left[\Lambda^{\alpha-1}(\tau)+\frac{1}{2} \Lambda^{-\alpha / 2-1}(\tau)\right] \frac{d \Lambda}{d \tau} d \tau$

where $\alpha$ is the strain parameter characterizing the nonlinear stress-stretch response, $\Lambda(t)$ is a continuous function of time, and $E(t)$ is the tensile relaxation modulus, characterizing the timedependent nature of the response. According to this model, any nonlinearity in the deformation behavior originates from the nonlinearity in the stress-strain response. Note that the nonlinear stress-strain response is similar in form to that proposed by Ogden [40] (Eq. (12)). In a relaxation test, stretch is first increased to $\Lambda\left(t_{0}\right)=\Lambda_{0}$ and then held constant throughout the relaxation period $\left(t>t_{0}\right)$. For this relaxation period, the relaxation stress becomes:

$\sigma(t)=\frac{2}{3} E(t)\left[\Lambda_{0}^{\alpha-1}+\frac{1}{2} \Lambda_{0}^{-\alpha / 2-1}\right]$

The tensile relaxation modulus will be represented here by a Maxwell standard linear solid (SLS) rheological model, consisting of a linear spring element of stiffness $E_{\mathrm{eq}}$, in parallel with a Maxwell element (i.e. another linear spring with stiffness $E_{2}$ in series with a Newtonian dashpot). The first spring characterizes the equilibrium response of the material which is proportional to the equilibrium modulus, $E_{\text {eq. }}$. The governing equation for the constitutive response of the SLS model is a first-order differential equation in time [57]. The relaxation modulus can be obtained from the solution of the governing equation for the SLS model:

$E(t)=E_{\mathrm{eq}}+E_{2} \exp \left(-\frac{t}{\eta / E_{2}}\right)$

where $\eta$ is the viscosity of the dashpot with units of MPas. Thus, the decay in the relaxation stress with time can be determined by Eq. (14) with the help of the relaxation modulus defined in Eq. (15).

\section{Results for constitutive response of liquid swollen PFSA}

\subsection{Using Mooney-Rivlin model}

Mooney-Rivlin plots, i.e. reduced stress as a function of $1 / \Lambda$, of the PFSA membrane investigated are depicted in Fig. 11A, based on the results of tensile tests conducted at various humidities [1] and in water at room temperature $\left(25^{\circ} \mathrm{C}\right)$ (presented in Section 2.2 ).
The response is clearly not linear for the vapor-equilibrated membranes. Thus, independent of the humidity, the material response does not capture the Mooney-Rivlin material model (Eq. (10)). In fact, we showed previously [30] that this material behavior may be captured by a modified form of the G'Sell-Jonas model for semicrystalline polymers. However, the Mooney-Rivlin plot for liquid-equilibrated membrane is approximately linear, indicating a correspondence to the material model suggested by Mooney-Rivlin. An approximate linear response is observed at all temperatures investigated in the range of $0.4<1 / \Lambda<0.85$ (Fig. 11B), corresponding to strains ranging from approximately 0.15 up to the break strain of between 2.0 and 2.5. We note that the break strains for liquid-equilibrated PFSA membranes are much lower than for typical rubbery polymers [48]. This observation eliminates the need for more sophisticated models based on nonGaussian representation, since the models based on the Gaussian network assumption were shown to deviate from the experimental uniaxial stress-stretch data at higher elongations $(\varepsilon>2.0-2.5)$ [48,49,51]. The empirical constants $C_{1}$ and $C_{2}$ obtained from the Mooney-Rivlin plots of the experimental data are depicted in Fig. 12 as a function of temperature.

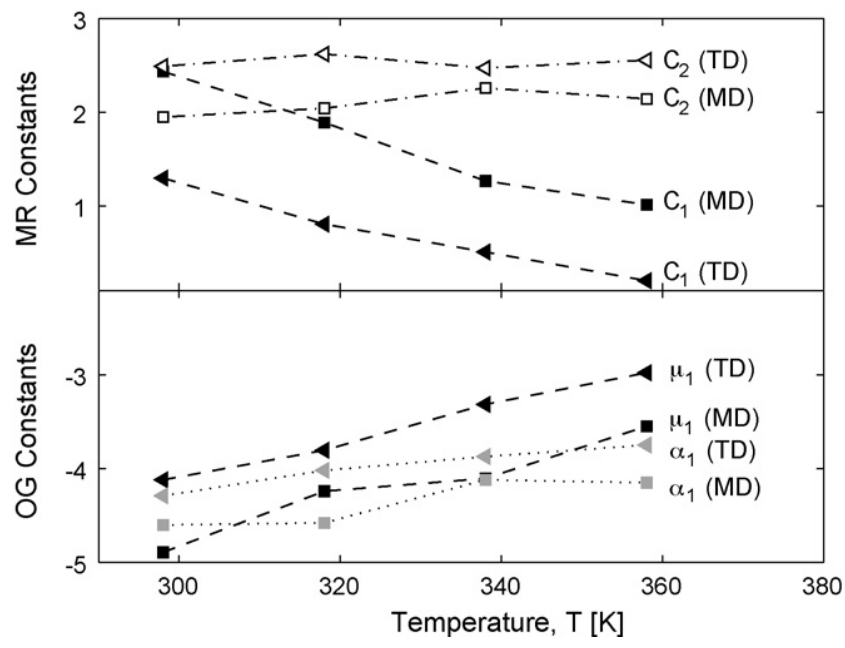

Fig. 12. Best-fit material parameters for Mooney-Rivlin (MR) and Ogden's model (OM) obtained from the experimental data as a function of temperature for machine (squares) and transverse direction (triangles) (lines are guide for the eye only). 

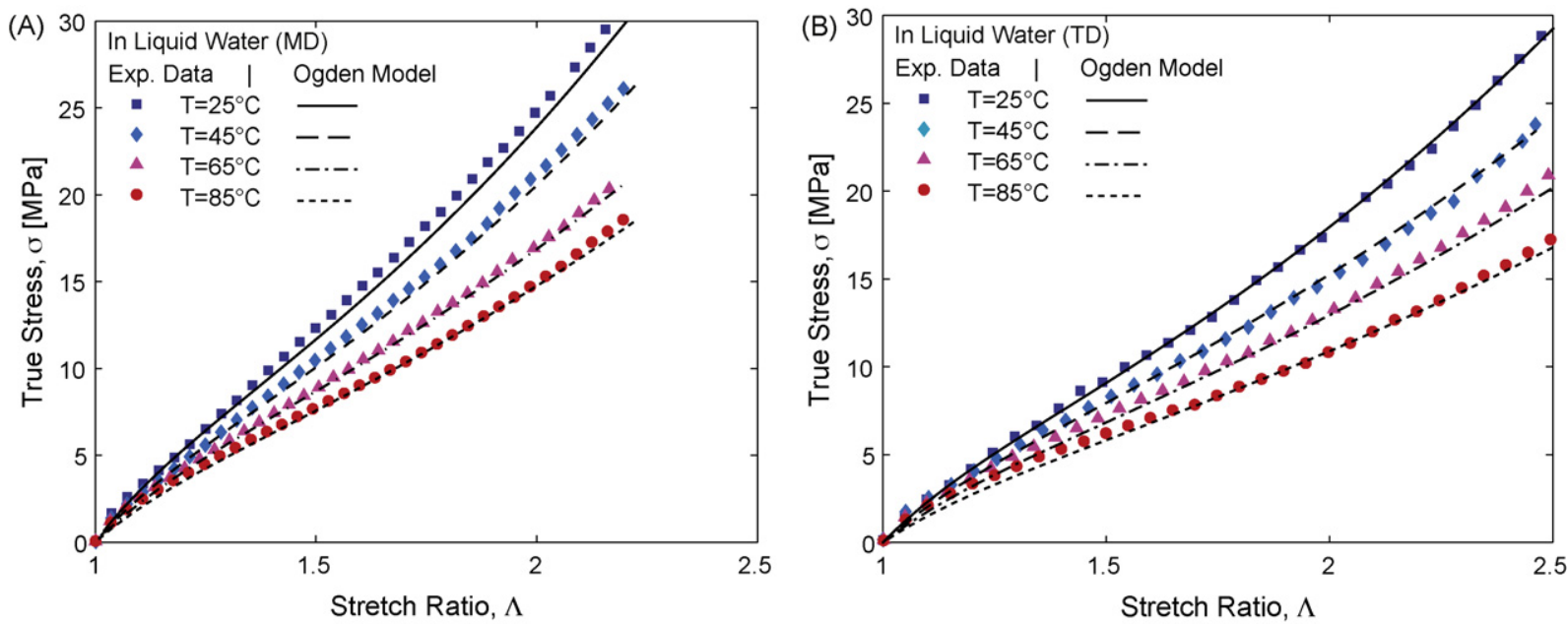

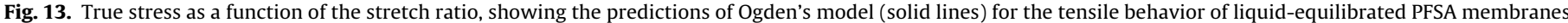
compared to experimental data at four temperatures for (A) machine, and (B) transverse direction.

\subsection{Using Ogden's model}

We conducted a least squares fit of Ogden's model (Eq. (12)) to the tensile test data of liquid-equilibrated PFSA membrane and there was no discernable difference between the results obtained for using different numbers of Ogden parameters in the range $n=1$, 2 and 3. Thus, for simplicity, we will only show the results for $n=1$ for which the material parameters are depicted in Fig. 12 and corresponding stress-stretch plots are shown in Fig. 13. Since the best-fit model parameters are both negative at all temperatures, the uniaxial stress-stretch relation can be rearranged into

$\sigma=\frac{2 G}{|\alpha|}\left(\Lambda^{0.5|\alpha|}-\Lambda^{-|\alpha|}\right)$

We note that Ogden's model fits our experimental data significantly better than the Mooney-Rivlin model does.

\subsection{Investigation of relaxation behavior}

So far, we have discussed the behavior of PFSA membrane during monotonic loading. We will now investigate whether the rubber-like behavior is retained during unloading. To this end, we use Eq. (14) together with the relaxation modulus defined in Eq. (15) to reproduce the experimentally obtained relaxation stress for the liquid-equilibrated PFSA membrane. Fig. 7 shows that the model predicts the experimental relaxation stress well for both tests. The membrane reaches steady-state relatively quickly and the equilibrium stress increases when the applied strain (stretch) increases. However, increasing the strain imposed at the beginning of relaxation test by a factor of 2.5 leads to only a doubling of the equilibrium stress. This suggests a stress-strain nonlinearity, which allows us to estimate the strain parameter $\alpha$ in Eq. (14). Interestingly, the value of $\alpha$ found from the relaxation tests is close to the one obtained from the prediction of Ogden's model (Eq. (16)) under the same test conditions (for the machine direction at $T=25^{\circ} \mathrm{C}$, see Fig. 12). This similarity indicates that the time-independent stress-strain response in Eq. (14) is approximately the same for both models. The best-fit material parameters for the relaxation modulus are found to be $E_{\mathrm{eq}}=33 \mathrm{MPa}, E_{2}=20.5 \mathrm{MPa}$ and $\eta=1100 \mathrm{MPa}$. Consequently, the experimental results suggest that nonlinearity must be considered when modeling the time-dependent deformation behavior of PFSA membranes.

\section{Discussion}

\subsection{Interpretation of the material parameters $C_{1}$ and $C_{2}$}

The experimental results suggest that, even though PFSA is not an elastomer, the constitutive response used for modeling rubbery behavior can be used for describing the constitutive response of PFSAs with high water content. We will in this section discuss how the material parameters for these models might be interpreted.

Although Ogden's model successfully reproduces the experimental data, it is worth briefly discussing the parameters of Mooney-Rivlin model, $C_{1}$ and $C_{2}$, whose physical interpretation have been investigated as applied to other polymers $[48,51,59]$. $C_{1}$ is commonly identified as the modulus of an ideal network, which is related to the structure and molecular weight of the material $[47,48,59,60]$, whereas $C_{2}$ may be attributed to the deviation from this ideal network behavior due to the non-affine deformation of the entanglements formed by the physical and chemical crosslinks [59]. For the PFSA membrane investigated in this study, $C_{1}$ decreases with increasing temperature (Fig. 12), exhibiting a similar trend to that seen for Young's modulus with temperature (Fig. 6). Furthermore, the low values of $C_{1}(<1 \mathrm{MPa})$, especially at elevated temperatures, may be an indication of enhanced chain mobility due to high water content and proximity to the glass transition temperature, which is around $95-105^{\circ} \mathrm{C}[5,29,61]$.

Even though a well-established physical interpretation of the $C_{2}$ term is not available, $C_{2}$ has generally been shown $[47,48,59,62]$ to diminish with increasing water uptake and eventually vanishing at high swelling. This suggests that swelling reduces the deviation of a Mooney-Rivlin material from the ideal rubber. However, the effect of swelling is not investigated since in this work, within the context of rubber elasticity, only the liquidequilibrated Nafion ${ }^{\circledR}$ membrane (for which the water volume fraction, $\phi_{\mathrm{w}}>0.40$ ) exhibits rubber-like behavior. The deformation behavior of the vapor-equilibrated membranes at low water contents $\left(\phi_{\mathrm{w}}<0.20\right)$ is similar to semicrystalline polymers, and $C_{1}$ and $C_{2}$ are consequently not defined for these conditions. In addition, $C_{2}$ appears to be independent of temperature in the range tested (Fig. 12). Furthermore, the ratio $C_{2} / C_{1}$ increases with decreasing $C_{1}$ for the Nafion ${ }^{\circledR} 112$ membrane in the present study, similar to the trends seen in several other classes of rubbery materials [59].

The elastic moduli of the liquid-equilibrated membrane can be estimated from the best-fit model parameters (Fig. 12) using the relations $E_{\mathrm{OM}}=3 \mu_{1} \alpha_{1} / 2$ for Ogden's model and $E_{\mathrm{MR}}=6\left(C_{1}+C_{2}\right)$ for 
the Mooney-Rivlin model. These moduli represent the slope of the low strain $(<0.05)$ portion of the stress-strain curve. However, the measured Young's moduli (Fig. 6) represent the tangent to the initial stress-strain curve and are higher than those predicted by these models. This difference may also be interpreted as the deviation from rubber elasticity model at very low strains, and may be due to the assumptions of the models which neglect the other higher order effects $[48,63]$.

\subsection{Constitutive response of liquid-equilibrated PFSA membrane}

Our experimental observations suggest that the water content (or swelling) of a membrane in liquid water is much higher than that of a membrane saturated with water vapor at high relative humidities (90-95\% RH), consistent with the trends reported in the literature $[25,26,42]$. This apparent difference in swelling which can be associated with Schroeder's Paradox - alters the deformation behavior of the membrane significantly. Furthermore, findings in this work on liquid-equilibrated membranes, together with the results from our previous work on the vapor-equilibrated membranes [30], suggest that the characteristic features of the stress-strain behavior of PFSA membrane appears to be fundamentally different in liquid water than in saturated water vapor.

PFSA membranes have a PTFE-like backbone with attached perfluorinated side chains [32,64-66]. Thus, by assuming that the PTFE-like backbone of the swollen PFSA membrane exhibits similar deformation behavior to that of PTFE, we can explain some of our experimental observations for the PFSA membrane by using the reported data on the mechanical behavior of PTFE [67-71].

First, we note that the yield limit, $Y$, and hardening modulus, $G$, for PTFE (which is the backbone of PFSA) at $21^{\circ} \mathrm{C}$ were reported to be 13.5 and $5.0 \mathrm{MPa}$, respectively [43]. Both values are almost twice that of dry PFSA, see Eqs. (8) and (9). A similar relationship between the moduli of PTFE and dry PFSA was discussed in our previous work [72]. We also observe that the temperature-driven decrease in Young's Modulus of PTFE $[67,68,71]$ is similar to that observed for PFSA membranes at low humidities (Fig. 6).

The morphology of a highly swollen PFSA has been described in the literature as comprised of crystalline rod-like aggregates, with water domains among them [32]. Upon stretching the PFSA, these rods will naturally orient into the stretching direction. Also, it has been noted that the deformation mechanisms in PTFE may be dominated by the orientation of the amorphous regions together with a secondary slip mechanisms within the crystalline regions [67]. Rae and Brown [67] suggested that high crystallinity in PTFE leads to an increase in stiffness at small strains. On the contrary, at large strains, lower crystallinity results in higher stiffness, since less additional deformation can be accommodated in the oriented amorphous regions of a low-crystalline PTFE. For PFSA membranes, both Young's modulus and yield limit (at onset of initial nonlinearity) decrease significantly with increasing water content (from vapor-to-liquid transition) which may be attributed to an overall decrease in the crystallinity of the membrane (e.g. $Y^{\text {liq }}<Y^{\text {vap }}$, see Figs. 6 and 9). However, liquid-equilibrated membrane exhibits more hardening at large strains than vapor-equilibrated membranes (e.g. $G_{T}^{\text {liq }}>G_{T}^{\text {vap }}$, see Fig. 8). This could be due to the role of the increasing volume fraction of amorphous regions in the liquidequilibrated membranes analogous to the behavior described in Rae and Brown [67].

Another hypotheses for the increase in hardening in PFSA membranes could be proposed based on the observations for the mechanical behavior of porous materials: it is suggested that a low amount of water absorbed by the system might act as a plasticizer at low strains (e.g. a continuous decrease in Young's modulus with increasing water content as shown in Fig. 6), whereas an anti-plasticizer effect can be seen at high strains in the form of hardening due to an increase in the structural order requiring more energy for the deformation and fracture [73,74]. Even though we have observed an increase in the hardening behavior of PFSA membranes in liquid water, we also have found that deformation energy (area under the stress-strain curve) of PFSA membranes does not increase significantly when immersed in liquid water. Thus, validation of this hypothesis requires additional experimental work that focuses on the fracture behavior of the PFSA membrane and is therefore left for future work.

The crystallinity of EW 1100 PFSA membranes has been shown to range between 3 and $12 \%$ depending on the water absorption and processing techniques $[36,75,76]$ and is reported to decrease with increasing water content [36,75,76]. Recently, Kim et al. [36] studied the nanostructure of PFSA membranes through smallangle neutron scattering experiments. They observed no apparent crystalline structure for highly swollen $\left(\phi_{\mathrm{w}} \approx 0.36\right)$ Nafion $^{\circledR} 112$ membranes, whereas crystalline features was observed for thicker Nafion ${ }^{\circledR}$ membranes, which might be associated with the effect of thickness on the rate of crystallization. This lends support to the explanation of the role of oriented amorphous regions on the hardening behavior of liquid-equilibrated PFSA at large-deformations discussed above. We propose therefore that the liquid-equilibrated PFSA membranes with high water volume fraction $\left(\phi_{\mathrm{w}}>40\right)$ can be considered as an amorphous polymer exhibiting characteristic features of elastomers, and their deformation behavior can therefore be modeled using the theories of rubber elasticity.

\section{Concluding remarks}

We have investigated the large-deformation tensile behavior of liquid-equilibrated PFSA membranes. Experimental data was obtained through tensile testing of Nafion ${ }^{\circledR} 112$ membranes immersed in liquid water at various temperatures in a custom-built temperature-controlled water bath. We observed a clear transition in the constitutive response of the membrane equilibrated in water vapor at high humidities to that in equilibrium with liquid water.

Our previous work [30] showed that vapor-equilibrated PFSA membranes exhibit semicrystalline-like deformation behavior, i.e. the stress-strain curves have three distinct features: (i) linear elastic (Hookean) regime, (ii) onset of initial nonlinearity which can be associated with a yield limit, followed by (iii) strain-hardening regime. However, in liquid-equilibrated PFSA membranes, a transition between the initial linear and subsequent nonlinear behavior is not readily discernable. Instead, the deformation is less semicrystalline-like and more rubber-like. Consequently, even though PFSA is not an elastomer, the constitutive response used for modeling rubbery behavior can be used for describing the constitutive response of PFSAs with high water content.

We show that the theoretical models of Mooney-Rivlin and Ogden capture the large-deformation uniaxial tensile behavior of liquid-equilibrated PFSA membranes in the temperature range of $25-85^{\circ} \mathrm{C}$. These models do not capture the constitutive response of the vapor-equilibrated membranes. Moreover, the models and experiments both show that Young's modulus and yield limit reduce with increasing temperature and water content. However, the strain-hardening modulus of liquid-equilibrated membrane at large strains is higher than that of vapor-equilibrated membranes. This stiffening mechanism observed at higher strains might be attributed to the increase in the fraction of amorphous regions (with negligible crystalline domains) upon equilibration with liquid water. Consequently, even though PFSA membranes may not be considered as a typical rubbery polymer, the experimental evidence suggests that the membrane, when immersed in water, becomes amorphous and exhibits rubber-like deformation behavior. 
These observations are of critical importance in understanding the long-term response of these materials in electrochemical devices where liquid water may form, such as PEM fuel cells. In addition, when building models to predict this response, the mathematical relationships describing rubber elasticity, along with the empirical constants detailed in this work, may be used in the models. We believe that this work may provide some insight into the long-standing debate on Schroeder's Paradox from a mechanics perspective, in that the membrane exhibits distinctly different material response for the two conditions. However, additional work is needed to fully elucidate the behavior.

\section{Acknowledgements}

Funding for portions of this work was provided by Federal Highway Administration, W.L. Gore, the CIRRUS project supported by the U.S. Department of Energy Hydrogen Program and the State of Delaware Development Office.

\section{References}

[1] Y. Tang, A.M. Karlsson, M.H. Santare, M. Gilbert, S. Cleghorn, W.B. Johnson, Materials Science and Engineering A 425 (2006) 297-304.

[2] R. Solasi, Y. Zou, X. Huang, K. Reifsnider, D. Condit, Journal of Power Sources 167 (2007) 366-377.

[3] D. Liu, S. Kyriakides, S.W. Case, J.J. Lesko, Y.X. Li, J.E. McGrath, Journal of Polymer Science, Part B-Polymer Physics 44 (2006) 1453-1465.

[4] P.W. Majsztrik, A.B. Bocarsly, J.B. Benziger, Macromolecules 41 (2008) 9849-9862.

[5] F. Bauer, S. Denneler, M. Willert-Porada, Journal of Polymer Science, Part B: Polymer Physics 43 (2005) 786-795.

[6] Y. Kawano, T. Wang, R.A. Palmer, S.R. Aubuchon, Polímeros: Ciência e Tecnologia 12 (2002) 96-101.

[7] X. Huang, R. Solasi, Y. Zou, M. Feshler, K. Reifsnider, D. Condit, S. Burlatsky, T. Madden, Journal of Polymer Science, Part B: Polymer Physics 44 (2006) $2346-2357$.

[8] U. Beuscher, S.J.C. Cleghorn, W.B. Johnson, International Journal of Energy Research 29 (2005) 1103-1112.

[9] W. Liu, K. Ruth, G. Rusch, Journal of New Materials for Electrochemical Systems 4 (2001) 227-232.

[10] M.F. Mathias, R. Makharia, H.A. Gasteiger, J.J. Conley, T.J. Fuller, C.J. Gittleman, S.S. Kocha, D.P. Miller, C.K. Mittelsteadt, T. Xie, S.G. Van, P.T. Yu, Electrochemical Society Interface 14 (2005) 24-35.

[11] A. Kusoglu, A. Karlsson, M. Santare, S. Cleghorn, W.B. Johnson, ECS Transactions $16(2008) 551-561$

[12] A. Kusoglu, A.M. Karlsson, M.H. Santare, S. Cleghorn, W.B. Johnson, Journal of Power Sources 170 (2007) 345-358.

[13] V.A. Sethuraman, J.W. Weidner, A.T. Haug, L.V. Protsailo, Journal of the Electrochemical Society 155 (2008) B119-B124.

[14] M. Crum, W. Liu, ECS Transactions 3 (2006) 541-550.

[15] Y. Tang, M.H. Santare, A.M. Karlsson, S. Cleghorn, W.B. Johnson, Journal of Fuel Cell Science and Technology 3 (2006) 119-124.

[16] A. Kusoglu, A.M. Karlsson, M.H. Santare, S. Cleghorn, W.B. Johnson, Journal of Power Sources 161 (2006) 987-996.

[17] T.A. Zawodzinski, T.E. Springer, J. Davey, R. Jestel, C. Lopez, J. Valerio, S. Gottesfeld, Journal of the Electrochemical Society 140 (1993) 1981-1985.

[18] L.M. Onishi, J.M. Prausnitz, J. Newman, Journal of Physical Chemistry B 111 (2007) 10166-10173.

[19] C.M. Gates, J. Newman, AIChE Journal 46 (2000) 2076-2085.

[20] T.E. Springer, T.A. Zawodzinski, S. Gottesfeld, Journal of the Electrochemical Society 138 (1991) 2334-2342.

[21] P. Schroeder, Zeitschrift Fur Physikalische Chemie 45 (1903) 75.

[22] A.Z. Weber, J. Newman, Journal of the Electrochemical Society 150 (2003) $1008-1015$.

[23] P.H. Choi, R. Datta, Journal of the Electrochemical Society 150 (2003) E601-E607.

[24] K.A. Mauritz, R.B. Moore, Chemical Reviews 104 (2004) 4535-4585.

[25] J.T. Hinatsu, M. Mizuhata, H. Takenaka, Journal of the Electrochemical Society 141 (1994) 1493-1498
[26] T.A. Zawodzinski, C. Derouin, S. Radzinski, R.J. Sherman, V.T. Smith, T.E Springer, S. Gottesfeld, Journal of the Electrochemical Society 140 (1993) 1041-1047.

[27] R. Solasi, Y.Zou, X.Y. Huang, K. Reifsnider, Mechanics of Time-Dependent Materials 12 (2008) $15-30$.

[28] M.B. Satterfield, J.B. Benziger, Journal of Polymer Science, Part B-Polymer Physics 47 (2009) 11-24.

[29] S. Kundu, L.C. Simon, M. Fowler, S. Grot, Polymer 46 (2005) 11707-11715.

[30] A. Kusoglu, Y. Tang, M.H. Santare, A.M. Karlsson, S. Cleghorn, W.B. Johnson, Journal of Fuel Cell Science and Technology 6 (2009) 011012-011018.

[31] V. Barbi, S.S. Funari, R. Gehrke, N. Scharnagl, N. Stribeck, Polymer 44 (2003) 4853-4861.

[32] P.C. van der Heijden, L. Rubatat, O. Diat, Macromolecules 37 (2004) 5327-5336

[33] C. Gsell, J.J. Jonas, Journal of Materials Science 14 (1979) 583-591.

[34] A.Z. Weber, J. Newman, Journal of the Electrochemical Society 151 (2004) 311-325.

[35] G. Gebel, Polymer 41 (2000) 5829-5838.

[36] M.H. Kim, C.J. Glinka, S.A. Grot, W.G. Grot, Macromolecules 39 (2006) 4775-4787.

[37] A. Siu, J. Schmeisser, S. Holdcroft, Journal of Physical Chemistry B 110 (2006) 6072-6080.

[38] M. Mooney, Journal of Applied Physics 11 (1940) 582-592.

[39] R.S. Rivlin, Philosophical Transactions of the Royal Society of London Series A-Mathematical and Physical Sciences 241 (1948) 379-397.

[40] R.W. Ogden, Proceedings of the Royal Society of London Series A-Mathematical and Physical Sciences 326 (1972) 565-584.

[41] A.E.T. Takamatsu, Journal of Applied Polymer Science 24 (1979) 2221-2235.

[42] D.R. Morris, X.D. Sun, Journal of Applied Polymer Science 50 (1993) 1445-1452

[43] R.N. Haward, Macromolecules 26 (1993) 5860-5869.

[44] R.N. Haward, G. Thackray, Proceedings of the Royal Society of London Series A-Mathematical and Physical Sciences 302 (1968) 453-472.

[45] H.M. James, E. Guth, Journal of Applied Physics 15 (1944) 294-303.

[46] E. Guth, H.M. James, Industrial and Engineering Chemistry 33 (1941) 624-629.

[47] J.H. Weiner, J. Gao, Macromolecules 23 (1990) 18601865

[48] L.R.G. Treloar, The Physics of Rubber Elasticity, Oxford University Press, New York, 2005.

[49] E.M. Arruda, M.C. Boyce, Journal of the Mechanics and Physics of Solids 41 (1993) 389-412.

[50] H.M. James, E. Guth, Journal of Polymer Science, Part B-Polymer Physics 34 (1996) 7-36.

[51] B. Meissner, Polymer 41 (2000) 7827-7841

[52] R. Bloch, W.V. Chang, N.W. Tschoegl, Journal of Rheology 22 (1978) 1-32.

[53] W.V. Chang, R. Bloch, N.W. Tschoegl, Journal of Polymer Science, Part B-Polymer Physics 15 (1977) 923-944.

[54] W.V. Chang, R. Bloch, N.W. Tschoegl, Rheologica Acta 15 (1976) 367-378.

[55] N. Nakajima, Polymer International 36 (1995) 105-116.

[56] N.W. Tschoegl, Mechanics of Time-Dependent Materials 1 (1997) 3-31.

[57] A. Drozdov, Viscoelastic Structures: Mechanics of Growth and Aging, Academic Press, San Diego, CA, 1998, p. 596.

[58] W.V. Chang, R. Bloch, N.W. Tschoegl, Proceedings of the National Academy of Sciences of the United States of America 73 (1976) 981-983.

[59] M.H. Wagner, Journal of Rheology 38 (1994) 655-679.

[60] Y.Q. Zhao, B.E. Eichinger, Macromolecules 25 (1992) 6996-7002.

[61] S.C. Yeo, A. Eisenberg, Journal of Applied Polymer Science 21 (1977) 875-898.

[62] N.W. Tschoegl, C. Gurer, Macromolecules 18 (1985) 680-687.

[63] H.M. James, E. Guth, Journal of Chemical Physics 11 (1943) 455-481.

[64] H.W. Starkweather, Macromolecules 15 (1982) 320-323.

[65] A. Gruger, A. Regis, T. Schmatko, P. Colomban, Vibrational Spectroscopy 26 (2001) 215-225.

[66] Q. Chen, K. Schmidt-Rohr, Macromolecular Chemistry and Physics 208 (2007) 2189-2203.

[67] P.J. Rae, E.N. Brown, Polymer 46 (2005) 8128-8140.

[68] P.J. Rae, D.M. Dattelbaum, Polymer 45 (2004) 7615-7625

[69] T. Kletschkowski, U. Schomburg, A. Bertram, Mechanics of Materials 34 (2002) 795-808.

[70] A. Khan, H.Y. Zhang, International Journal of Plasticity 17 (2001) 1167-1188.

[71] J.S. Bergstrom, L.B. Hilbert Jr., Mechanics of Materials 37 (2005) 899-913.

[72] A. Kusoglu, M.H. Santare, A.M. Karlsson, S. Cleghorn, W.B. Johnson, Journal of Polymer Science, Part B: Polymer Physics 46 (2008) 2404-2417.

[73] P. Pittia, G. Sacchetti, Food Chemistry 106 (2008) 1417-1427.

[74] Y.P. Chang, P.B. Cheah, C.C. Seow, Journal of Food Science 65 (2000) 445-451.

[75] T.D. Gierke, G.E. Munn, F.C. Wilson, Journal of Polymer Science, Polymer Physics Edition 19 (1981) 1687-1704.

[76] M. Fujimura, T. Hashimoto, H. Kawai, Macromolecules 14 (1981) 1309-1315. 